\title{
The application of compaction device for highway structural layer in the road construction of Yun-Mao Highway
}

\author{
Boqian $\mathrm{He}^{1^{*}}$ and Jian $\mathrm{Lou}^{2}$ \\ ${ }^{1}$ Guangdong Guanyue Road Bridge Limited Company, Guangzhou, Guangdong Province, 511400, China \\ ${ }^{2}$ Guangdong Yun-Mao Highway Limited Company. Yunfu, Guangdong Province, 527200, China
}

\begin{abstract}
The compaction device for highway structural layer is the hinge connection of the end of the hydraulic breaker rod of a conventional excavator and the base of a compaction device. During operation, the steel panel of the compaction device is positioned on top of the construction area, which is then compacted by controlling the hydraulic breaker of the excavator. This device can quickly and effectively solve the common quality issues such as the insufficient compactness of the earth shoulder in highway construction projects.
\end{abstract}

\section{Technology Background}

In highway engineering, there are small-area, narrow, long and irregular sections of earthwork that cannot be rolled by machines. In these sections, hand-held vibrational compaction techniques are normally used to perform compaction on earth shoulders, lane separators and abutment backfilled soil [2]. These techniques have drawbacks such as long manual operating time and high labour intensity for the workers. Particularly in construction areas with guardrails, as well as in the compaction of road structural layer at special locations in municipal engineering projects, these techniques significantly limit the room for construction.

\section{Design Principle}

The design principle of this device is utilizing the hydraulic breaker rod of an excavator with an additional installation of a steel compaction panel [1]. It achieves the purpose of compaction by passing the vibrational force from the hydraulic breaker rod of the excavator to the steel panel, and finally to the surface and the interior of the road structural layer.

\section{Outcomes}

In the Yun-Mao Highway project, this device was used to compact the earth shoulder in road construction. It solved the common quality issue of insufficient compactness of the earth shoulder and effectively prevented the quality issues such as the erosion of the earth shoulder edge due to the sinking of the low-pressure earth shoulder (Figure 1) [3]. (a).

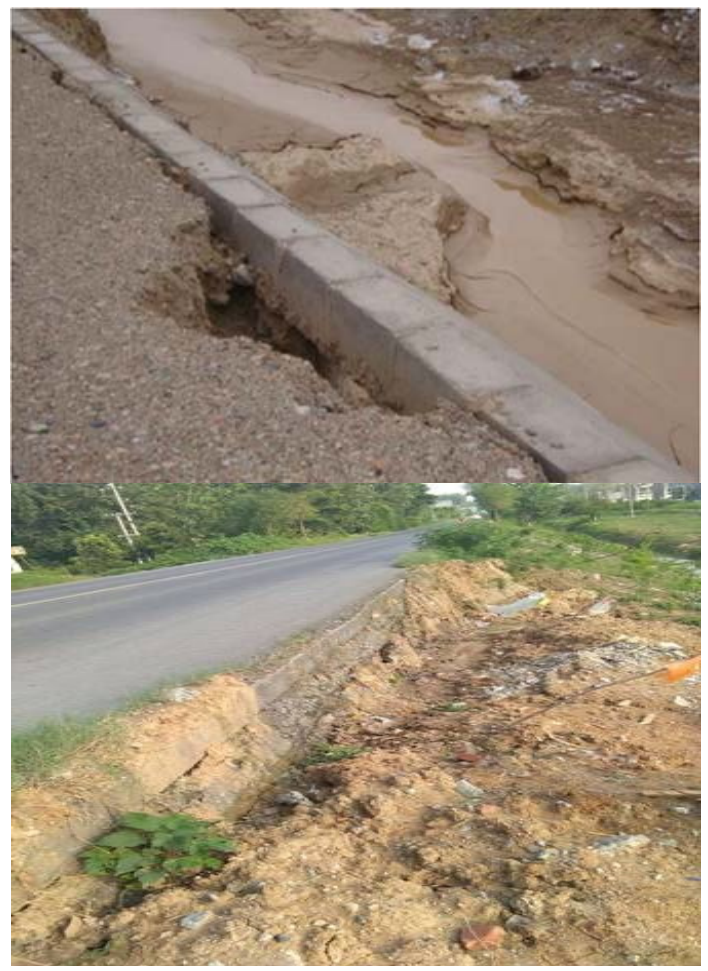

Figure 1. Common highway quality issues such as (a) the erosion of earth shoulder and (b) the lack of compactness of earth shoulder.

The compaction device for highway structural layer consists of a main panel, the base installed on the centre of the main panel, and the connector that connects the base with the hydraulic breaker rod of an excavator. There is a ball-shaped groove in the base and a ball-shaped bulge at the end of the hydraulic breaker rod. The hydraulic breaker rod is hinged to the ball-shaped base on the main panel. When in use, this device is connected to the hydraulic breaker rod of an excavator. During operation, the steel

\footnotetext{
* Corresponding author: 269661476@qq.com
} 
panel is placed on the top surface of the construction area. By controlling the hydraulic breaker rod of the excavator, the construction area can be pressed and compacted quickly.

Here the earth shoulder compaction work for the TJ14 section of the Guangdong Yun-Mao Highway project is taken as an example. By collecting the data regarding the improvement in compactness and flatness as well as the reduction in change factor from the experimental construction section of the earth shoulder compaction work, the results of the two construction techniques are assessed. The experimental construction section of the earth shoulder compaction work is $500 \mathrm{~m}$ long each. The panel compaction technique with hydraulic rod of excavator was used at pole number $\mathrm{K} 101+500 \sim$ $\mathrm{K} 102+000$ on the left. While the hand-held vibrational compaction technique was used at pole number $\mathrm{K} 102+000 \sim \mathrm{K} 102+500$ on the left. The maximum dry soil density was $\rho=2.03 \mathrm{~g} / \mathrm{cm}^{3}$ and the soil water content was $\mathrm{W}=7.1 \%$. The digging and sand filling technique was used to measure the compactness of earth shoulder and the 3metre ruler technique was used to measure the flatness of the earth shoulder surface [4]. The comparison of the results from the two techniques is shown in Table 1.

Through analysing the implementation and measurements in the experimental construction section of the earth shoulder compaction work, the following conclusions can be drawn:

(1) Comparing the construction time for the same 500 -metre experimental section of the earth shoulder compaction work, the use of panel compaction technique with hydraulic rod of excavator can significantly reduce the construction time and improve the construction efficiency by $75 \%$.

(2) The use of panel compaction technique with hydraulic rod of excavator can achieve more stable earth shoulder. The representative value for compactness was significantly improved by
$14.9 \%$, while the change factor of compactness was reduced by $52.9 \%$.

(3) The use of panel compaction technique with hydraulic rod of excavator improved the surface flatness of earth shoulder by $31.7 \%$. The earth shoulder had a smoother profile. The risk of side-slope erosion as a result of hydrops in the earth shoulder was effectively avoided.

\section{Financial Benefit Analysis}

Taking the earth shoulder compaction work for the TJ14 section of the Guangdong Yun-Mao Highway project as an example, the differences between the equipment cost, fuel cost, labour cost of the conventional hand-held vibrational compaction technique and the technique of steel compaction panel attached to the hydraulic breaker rod are as below. The earth shoulder of the TJ14 section of YunMao Highway has a length of $41.3 \mathrm{~km}$ on one side. The conventional hand-held vibrational compaction technique requires a hand-held vibrational compaction machine (around ¥ 8000 each), four assistant workers ( $¥$ 200/working day), fuel cost of around $¥ 200$ per machine shift. Around $500 \mathrm{~m}$ can be compacted each working day. The steel panel compaction technique connected to hydraulic rod of an excavator requires an oneoff expense of around $¥ 5000$ each, an assistance worker at the construction site ( $¥ 200 /$ day), an excavator ( $¥ 1200$ per machine shift, including fuel cost). Around $2000 \mathrm{~m}$ of earth shoulder can be compacted each day. The comparison of the financial costs of the two techniques are shown in Table 2. From Table 2, the use of steel panel compaction technique attached to the hydraulic rod of excavator can save around $¥ 57000$ of financial costs in the TJ14 section.

Table 1. Comparison of results from the two techniques.

\begin{tabular}{lllll}
\hline Construction techniques & $\begin{array}{l}\text { Construction } \\
\text { time }(\mathrm{h})\end{array}$ & $\begin{array}{l}\text { Representative value of } \\
\text { compactness }(\%)\end{array}$ & $\begin{array}{l}\text { Change factor of } \\
\text { compactness Cv }\end{array}$ & $\begin{array}{l}\text { Average } \\
\text { flatness } \\
(\mathrm{mm})\end{array}$ \\
\hline $\begin{array}{l}\text { Hand-held vibrational } \\
\text { compaction technique }\end{array}$ & 8 & 83.2 & 13.30 & 12.0 \\
$\begin{array}{l}\text { Panel compaction technique } \\
\text { with hydraulic rod of } \\
\text { excavator }\end{array}$ & 2 & 95.6 & 6.26 & 8.2 \\
\begin{tabular}{l} 
Percentage change $(\%)$ \\
\hline
\end{tabular} & -75.0 & +14.9 & -52.9 & -31.7 \\
\hline
\end{tabular}


Table 2. Comparison of the financial costs of the two techniques.

Comparison of techniques

Hand-held vibrational compaction technique

Panel compaction technique with hydraulic rod of excavator

Cost difference
Equipment and labour costs of earth shoulder compaction work in the TJ14 section of Yun-Mao Highway

$8000+(4$ people * $¥ 200 /$ working day $+¥ 200 /$ shift $) / 500 \mathrm{~m} *$

$41300 \mathrm{~m}=¥ 90600$

$5000+(¥ 1200 /$ shift +1 person * $¥ 200 /$ working day $/ 2000 \mathrm{~m} *$

$41300 \mathrm{~m}=¥ 33910$

$¥ 56690$

\section{Social Benefit Analysis}

The use of steel panel compaction technique attached to the hydraulic rod of excavator addresses the common quality issue of the lack of compactness in the earth shoulder, effectively avoids the roadside erosion, and guarantees the quality of the earth shoulder construction work [5]. It also reduces the potential quality issues during construction and lowers the maintenance costs as a result [6], while at the mean time achieves the quick and productive compaction of the earth shoulder. The construction time is reduced and certain social benefits are achieved. The technological improvement in this sector is also promoted at the same time.

\section{Supplementary Images of the Structure}

(a).

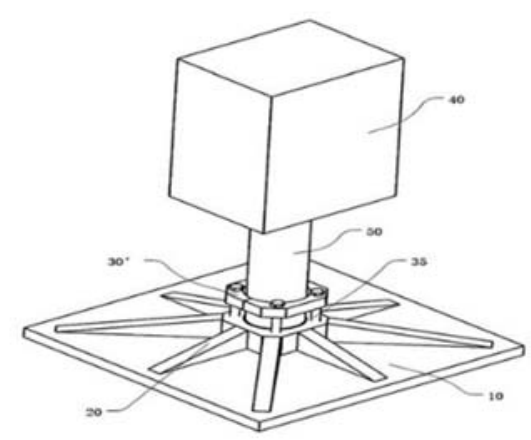

(b).

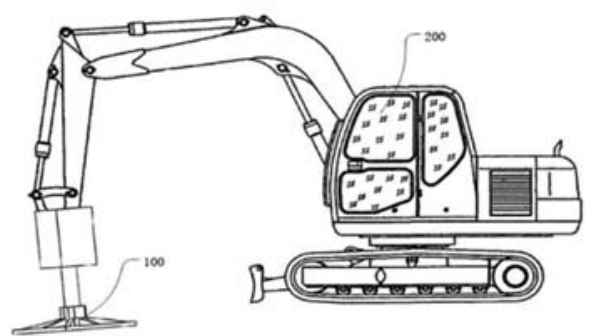

Figure 2. Diagram of (a) the compaction device and (b) the overall structure.

In the supplementary image, each of the labelled components is shown below:

10. The main panel; 20. Base; 30'.Connecting component; 35. Connecting pillar; 40. Breaker rod; 100. Compaction device for highway structural layer; 200. Excavator.

\section{Photos of Construction on the Scene}

(a).

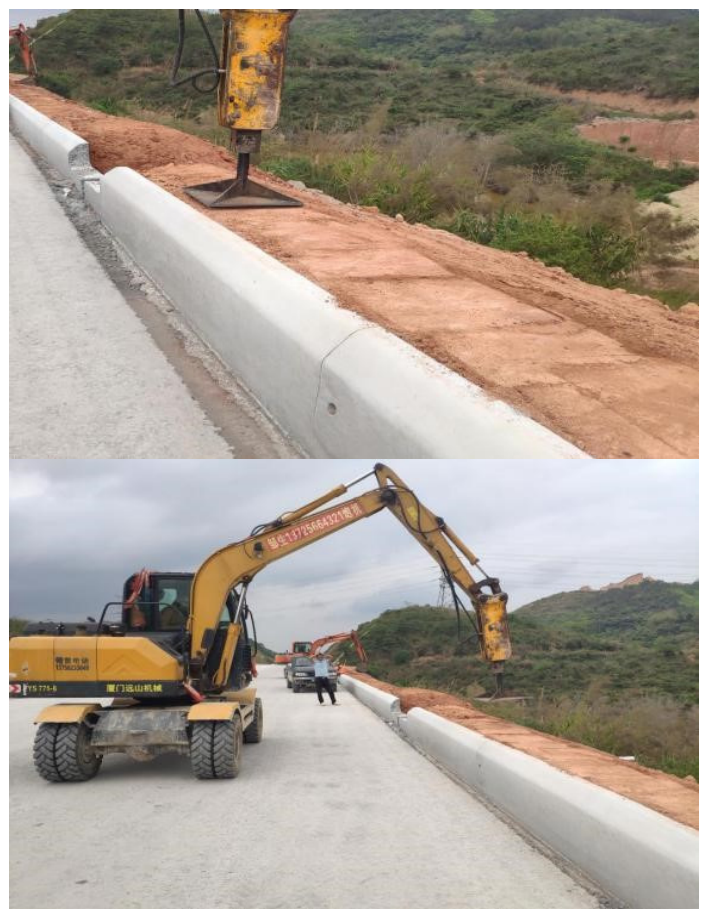

Figure 3. (a) Paving construction scene and (b) the sprinkled liquid cement.

\section{Conclusion}

The compaction device for highway structural layer utilises a compacting steel panel attached to the hydraulic breaker rod of an excavator to pass on the force and achieve compaction of the construction surface. This device was first used in the compaction of earth shoulder in the Yun-Mao Highway project. From experimental implementation, the construction efficiency, construction quality and economic benefit have been improved, in comparison to the use of conventional hand-held vibrational compaction technique. In addition, certain social benefits have been achieved, demonstrating its value for further promotion. In the field of highway engineering, due to the inconsistency in the material properties of structural layers, structural thickness and the quality requirement [7], this device alone cannot be used in the structural layer engineering in all areas. The power of the hydraulic breaker rod of the excavator, compacting angle, 
compacting time and the size of the compacting panel need to be researched and optimised, in order to allow the best use of this device.

\section{Acknowledgements}

The authors would like to acknowledge the Guangdong Yun-Mao Highway Limited Company, Guangdong Guanyue Road Bridge Limited Company for their assistance.

\section{References}

1. National Intellectual Property Administration of the People's Republic of China. Guangdong Guanyue Road Bridge Limited Company. Notification of Acceptance of Patent Application for the Compaction Device for Highway Structural Layer (Patent number: 202010362055.2).

http://cprs.patentstar.com.cn/Search/Detail?ANE=9G IH9GFC9HHH9IGF9GHF9HFD9DFC9ICH9GHG3 ADA9FFGAEIA.

2. Ministry of Transport of the People's Republic of China. (2019) Recommended Industry Standards. JTG/T3610-2019 Technical Specifications for Construction of Highway Sub grades. http://xxgk.mot.gov.cn/2020/jigou/glj/202006/P0202 00623699287135059.pdf.

3. J. Li, W. Tian, Experiment on the erosion and destruction mechanism of earth shoulder. Journal of Chang'an University (Natural Science Edition). 2 (2004).

https://kns.cnki.net/kcms/detail/detail.aspx?dbcode $=$ CJFD\&dbname $=$ CJFD2004\& filename $=$ XAGL20040 $2006 \& v=$ EaXxgOV0XeYlqUcs8adoHb $\% 25 \mathrm{mmd} 2 \mathrm{Fp}$ 4GV1rFKPOBpj7WB7rnXbr5KnPFqS7wHrmBc0gu $\mathrm{mb}$.

4. Ministry of Transport of the People's Republic of China. (2019) Industry Standards of the People's Republic of China. JTG 3450-2019 Field Test Methods of Highway Subgrade and Pavement. http://xxgk.mot.gov.cn/2020/jigou/glj/202006/t20200 623 3313200.html.

5. J. Zhu, L. Ting, L. Fu, X. Wang, W. Gao, Dynamic pre-caution for road foundation based on IFOA algorithm. Journal of Henan Polytechnic University (Natural $\quad$ Science). $\quad 2 \quad$ (2020). https://kns.cnki.net/kcms/detail/detail.aspx?dbcode= CJFD\&dbname $=$ CJFDLAST2020\& filename $=$ JGXB $202002020 \& \mathrm{v}=\mathrm{tWzkqXPD} \% 25 \mathrm{mmd} 2 \mathrm{FrBw} 5 \mathrm{tDqQ} \%$ 25mmd2BNtuuk\%25mmd2FIxyBpb8821XgIEqhbY $\% 25 \mathrm{mmd} 2 \mathrm{FWsUMRhrcLZovxdS} \% 25 \mathrm{mmd} 2 \mathrm{~F} 2 \mathrm{vyBY}$.

6. Y. Song, Anti-erosion measures for filled road foundation construction Transport World 28 (2019). https://kns.cnki.net/kcms/detail/detail.aspx?dbcode= CJFD\&dbname $=$ CJFDLAST2019\& filename $=$ JTSJ2 $01928009 \& \mathrm{v}=\mathrm{Bf} 1 \% 25 \mathrm{mmd} 2 \mathrm{Br} 5 \mathrm{q} 79 \mathrm{Rw} \% 25 \mathrm{mmd} 2 \mathrm{~F}$ HwnEF\%25mmd2B3jKIRk3umDQER0YWGFyWm U2X\%25mmd2Bjv6iDzIrulNHfN1bPfyTM.
7. Ministry of Transport of the People's Republic of China. (2017) Industry Standards of the People's Republic of China. JTG F80/1-2017 Inspection and Evaluation Quality Standards for Highway Engineering. Section 1: Civil Engineering. http://www.nssi.org.cn/nssi/front/gbdetail.jsp?A001= $\mathrm{NzgzNjMwOQ}==$. 